\title{
La Dirección de Inteligencia de la Policía de la Provincia de Buenos Aires y el espionaje a la movilización indígena en 1992
}

The Intelligence Boureau of the Police of the Buenos Aires Provinceand espionage of Indigenous mobilization in 1992

\section{Diana Lenton and Mariano Nagy}

\section{OpenEdition}

\section{Journals}

\section{Electronic version}

URL: https://journals.openedition.org/corpusarchivos/4699

DOI: 10.4000/corpusarchivos.4699

ISSN: $1853-8037$

Publisher

Diego Escolar

\section{Electronic reference}

Diana Lenton y Mariano Nagy, «La Dirección de Inteligencia de la Policía de la Provincia de Buenos

Aires y el espionaje a la movilización indígena en 1992», Corpus [En línea], Vol. 11, №. 1 | 2021,

Publicado el 03 julio 2021, consultado el 03 julio 2021. URL: http://journals.openedition.org/

corpusarchivos/4699 ; DOI: https://doi.org/10.4000/corpusarchivos.4699

This text was automatically generated on 3 July 2021.

Licencia Creative Commons: Atribución-NoComercial 2.5 Argentina (CC BY-NC 2.5 AR) 


\section{La Dirección de Inteligencia de la Policía de la Provincia de Buenos}

\section{Aires y el espionaje a la movilización indígena en $1992^{1}$}

The Intelligence Boureau of the Police of the Buenos Aires Provinceand espionage of Indigenous mobilization in 1992

Diana Lenton and Mariano Nagy

\section{EDITOR'S NOTE}

Fecha de recepción del original: 06/03/2021

Fecha de aceptación para publicación: 18/05/2021

\section{Introducción}

1 A partir de la segunda mitad del siglo XX, en Argentina comenzaron a formarse y se consolidaron ciertas organizaciones de activismo político indígena. Estas atravesaron dictaduras y períodos democráticos y fueron sistemáticamente observadas, controladas y eventualmente reprimidas por el aparato estatal nacional o provincial, en la medida en que las mismas desafiaron ciertos estereotipos de expresión pública de lo indígena creados y difundidos por la ideología estatal-nacional. Sus líderes fueron criminalizados y aún en nuestros días son objeto de sospecha permanente. Esta sospecha obedece a la tendencia general a subestimar sus iniciativas originales y sus objetivos autónomos para priorizar una lectura que pone al "indigenismo" en el rol de vector de la subversión ideológica o la penetración extranjera (Espósito y Catela, 2013). 
2 El foco de este trabajo es el fondo documental de la Dirección de Inteligencia de la Policía de la Provincia de Buenos Aires (DIPPBA), en particular los registros producidos por las acciones de seguimiento e inteligencia respecto a los festejos y contrafestejos motivados por el V Centenario de la Conquista de América, en 1992. Se trata de legajos que forman parte de los documentos desclasificados que están a cargo de la Comisión Provincial por la Memoria y que reúnen información acerca de distintas acciones de inteligencia desplegadas en la provincia de Buenos Aires para espiar, especialmente, a quienes mostraban una postura crítica en relación con la llegada de Colón a América, pero también a aquellos que reproducían el tono celebratorio de la efeméride del 12 de octubre de 1492.

3 La DIPPBA atribuía a las actividades y grupos observados la gestación de frentes opositores o revolucionarios con apoyo internacional vinculados al terrorismo y al narcotráfico, categorizados como "nuevas amenazas" a la seguridad internacional, en una etapa pos guerra fría pero previa a la "Guerra contra el terror" lanzada por la administración de George W. Bush luego del atentado a las Torres Gemelas en septiembre de 2001.

4 A través del seguimiento de un archivo determinado, nuestra intención es invitar a pensar sobre la incidencia de preconceptos presentes en el sentido común hegemónico acerca de los movimientos indígenas en el accionar típico de los servicios de inteligencia. Las nociones y procedimientos originados al calor de la lucha contra el comunismo en el marco de la guerra fría, bajo la Doctrina de la Seguridad Nacional (Muzzopappa, 2000) y su resignificación en la última década del siglo XX, al amalgamar el narcotráfico, el terrorismo y los movimientos indígenas, apuntan en ese camino y están presentes en los documentos de la DIPPBA.

\section{La DIPPBA}

5 Atravesando distintas denominaciones y variaciones en la amplitud de sus funciones y recursos, la Dirección de Inteligencia de la Policía de la Provincia de Buenos Aires (DIPPBA) fue creada en 1956 y disuelta en 1998, ${ }^{2}$ aunque conserva información desde 1932, cuando funcionaba como Dirección de Orden Público. Su contexto de origen es la dictadura del Gral. Pedro Eugenio Aramburu, cuando la intervención de la policía provincial por parte de las Fuerzas Armadas creó la Central de Inteligencia de la Policía de la Provincia de Buenos Aires con jerarquía de Dirección. Poco más de cuatro décadas después, en 1998 y bajo la presidencia de Carlos Menem, la Dirección de Inteligencia fue disuelta mediante una resolución del Ministerio de Seguridad.

6 En marzo de 2001, a través de la ley provincial 12.642, la Comisión Provincial por la Memoria (CPM) recibió de manera gratuita y por 99 años el edificio donde funcionaba la DIPPBA (calle $54 \mathrm{~N}^{\circ} 487$ entre 4 y 5, La Plata) para "el mantenimiento y digitalización del Archivo de la ex Dirección de Inteligencia de la Policía de la provincia de Buenos Aires que también se transfiere por esta Ley" y "hacer del archivo un centro de información con acceso público tanto para los afectados directos como para todo interesado en desarrollar tareas de investigación y difusión". ${ }^{3}$

7 La CPM postula que, en términos históricos y políticos, la creación de la DIPPBA en 1956, apenas producido el golpe de estado, se puede explicar a través de la articulación de una lógica de orden nacional, orientada a sostener la proscripción del peronismo, y 
otra de orden internacional, en relación con la Doctrina de Seguridad Nacional y la creación del enemigo interno en el marco de la Guerra Fría. El fondo combina la totalidad del archivo de inteligencia político-ideológica que la institución generó en el marco de algunas de sus misiones y funciones, con documentación de índole más administrativa, como por ejemplo aquella vinculada al personal de la institución y a gastos de gestión (CPM, s/f, p. 1).

8 En 2003 el archivo se abrió a consultas mientras se continuaba con la tarea de catalogación. Como la documentación arroja información sensible sobre las personas, la CPM decidió ampararse en la Ley de Habeas data (25.326), elaborar un protocolo y entregar copia de la documentación protegiendo la identidad de terceras personas mediante la disociación de datos (Jaschek et al., 2018, p. 4). En 2011 finalizó un relevamiento archivístico que brindó una pormenorizada desclasificación de los millones de folios distribuidos en el espacio de 3.300 contenedores y 90 cuerpos de estanterías con 600 estantes (Marengo y Castronuovo, 2015, pp. 111-112).

Llegamos a la DIPPBA ${ }^{4}$ a partir de la búsqueda de documentación sobre la persecución al movimiento indígena de la provincia, en continuidad con nuestras investigaciones previas sobre la represión a los indígenas durante la dictadura militar (Lenton, 2009; 2015) y sobre los antecedentes históricos del movimiento indígena en la provincia (Nagy, 2012; 2017; 2018a). Dada la política de protección de datos personales implementada por este reservorio, situado en el edificio donde funcionaba la ex DIPPBA, actual sede de la Comisión Provincial por la Memoria, el acceso a legajos personales está limitado a los involucrados y sus descendientes. Por eso, en 2016 iniciamos con el profesor Jorge Cayuqueo, artista y docente especializado en Educación Intercultural Bilingüe (EIB), una investigación en colaboración que nos permitió acceder a la documentación concerniente al espionaje policial sobre la familia Cayuqueo de la comunidad de Los Toldos, un caso paradigmático de represión del movimiento indígena. ${ }^{5}$ La documentación específica sobre el espionaje a la familia Cayuqueo a través de varias décadas fue entregada en copias en papel, mientras que otros materiales digitalizados por la CPM, entre ellos los legajos de personas espiadas en los años 90, sobre los cuales tratamos en este artículo, fueron entregados en formato electrónico. Algunos de estos materiales se publicaron parcialmente en Nagy (2018a).

Como sostiene una publicación propia que sintetiza su historia institucional,

(...) aunque con variantes en su transcurrir histórico, la función de la DIPPBA consistió básicamente en la planificación burocrática y realización de las tareas de búsqueda, reunión, calificación y difusión de la información sobre ciudadanos, organizaciones y acontecimientos en el territorio bonaerense. La información era generada fundamentalmente por las delegaciones de Inteligencia (sea por requerimiento de la Central, por el relevamiento de un caso o por el seguimiento rutinario de sectores o actividades), y también por el intercambio con otras direcciones de la propia policía o con agencias de inteligencia de otros organismos del Estado, provinciales o nacionales (CPM, s/f, p. 3).

11 En tal sentido, coincidimos con Lanteri y otros $(2005$, p. 10) en no adjudicarle a las tareas de la DIPPBA una modalidad panóptica, sino entenderlas como una tecnología de control anónima a través de acciones de vigilancia secreta, y con Funes (2006, p. 35), quien considera a los archivos de la DIPPBA como una "burocracia del mal" que arroja información acerca de la persecución de la sociedad civil en sus más variadas manifestaciones y que fue de notable incidencia en la represión realizada por la última dictadura militar (1976-1983). En esa línea puede visualizarse una combinación 
marcada por el sesgo ideológico de sus agentes y funcionarios, pero también, la dinámica burocrática y jerárquica inherente a los aparatos del Estado.

Finalmente, como explican Marengo y Castronuovo (2015, p. 109), la DIPPBA deviene en un

dispositivo arquitectónico con toda una ingeniería organizacional aplicada al espacio, atravesada por una noción de mundo que el Estado con su aparato represivo concibió y que tuvo sus implicancias directas con aquellos cuerpos custodiados, transformados en papeles y convertidos en delincuentes políticos.

Además, como su accionar excede largamente a las dictaduras y abarca gran parte del siglo XX, estas autoras optan por entender a la Dirección de Inteligencia como Archivos de control social, antes que como Archivos de la Represión ${ }^{6}$ (Marengo y Castronuovo, 2015, p. 111).

En función de los registros que analizaremos, es conveniente aclarar que la información proviene en su gran mayoría de dependencias o comisarías del conurbano o el interior bonaerense. Los legajos se vinculaban a "Mesas de trabajo" y "Factores". Estos últimos podían ser político, social, comunal, religioso, gremial, económico, laboral, policial, operacional o estudiantil, mientras que las Mesas recibían letras o denominaciones relacionadas a esos Factores. Por ejemplo la Mesa A abarca los factores político, comunal y estudiantil y contiene un registro de actividades de política partidaria, estudiantiles y de gobierno; la Mesa B se ocupa de los factores gremial, laboral y económico y reúne información correspondiente al mundo del trabajo, entidades gremiales, actividad sindical y fabril, y actividad económica; la Mesa "De" se ocupa de lo social y religioso (acciones de inteligencia sobre asociaciones cooperadoras, bibliotecas, clubes, entre otras entidades) y la Mesa "DS" refiere a "actividades subversivas". ${ }^{7}$

\section{Celebraciones del V Centenario}

El V Centenario de la llegada de los europeos a América impulsó una serie de festejos en España entre los que se destacan la Exposición Universal de Sevilla y un conjunto de acciones a partir de una comisión creada ad hoc para los eventos, ya en la década de 1980. Estos sucesos impactaron en otras áreas, como los Juegos Olímpicos de Barcelona ${ }^{8}$ y la organización de la II Cumbre Iberoamericana de Jefes de Estado realizada en Madrid en julio de 1992. La efeméride cumplió el propósito de "relanzar" la imagen de España en el mundo para superar las décadas de franquismo (Borja y Mascareñas, 1992) $\mathrm{y}$, a la vez, revivir nostálgicamente el protagonismo que España sostuvo durante los interminables festejos del $4^{\circ}$ Centenario (Trouillot, 1995, pp. 108 y ss.). La participación de instituciones argentinas en las celebraciones de ultramar desató críticas que fueron recogidas por los medios y recopiladas por los agentes. Por ejemplo, el diario El Día de La Plata publicó esta nota que fue archivada por la DIPPBA. ${ }^{9}$

"Explotación": Las celebraciones del Quinto Centenario del Descubrimiento de América han desatado una polémica. ¿Festejo o duelo? La cuestión (...) se ha trasladado al ámbito de la Universidad. Ayer, mientras se realizaba la presentación en el Museo de la muestra que la Universidad (UNLP) exhibirá en Sevilla, militantes estudiantiles de la Facultad de Ciencias Naturales repartían un panfleto en el que repudian la participación de la casa de altos estudios local en la Expo. "La ExpoSevilla y otros eventos que se preparan en Europa pretenden convertir el dolor y el luto en fiesta, y el saqueo y esclavitud en un gesto de amistad" (Diario El Día, 22-4-1992). 

confluyeron en las protestas diversos referentes y líderes originarios de todo el país que contaban con experiencias y trayectorias militantes en movimientos o encuentros propiamente indígenas, o en organizaciones políticas y sindicales surgidas en el marco de la movilización social de las décadas de 1960 y 1970 (Lenton, 2015; 2018), con una generación de jóvenes indígenas que ingresó en el activismo durante la "primavera alfonsinista", en movimientos de derechos humanos y partidos políticos (Nagy, 2018a). Las organizaciones desafiaron persistentemente las tipologías de "lo político" (Lazzari y Lenton, 2019) que relegaban al activismo indígena a una condición pasiva y pre-política (Nagy, 2013). Es importante señalar también que el activismo indígena contra el V Centenario tuvo como telón de fondo las reformas políticas neoliberales que propiciaron una conjugación del repliegue estatal con el resurgimiento de justas demandas que, a su tiempo, generaron una paradoja: la politización de las identidades en contextos de despolitización de la política (Briones, 2005). "El escenario (neoliberal) coadyuvó al crecimiento de los movimientos aborígenes al otorgar mayor legitimidad a demandas sociales formuladas como tales (particularmente en plena retracción del mercado de trabajo y aumento de la marginalidad socioeconómica)" (Escolar, 2005, p. 64).

Por tanto, en las últimas décadas del siglo XX, la ruptura de lazos sociales e identitarios típicos de estados de intervención y el auge neoliberal ${ }^{12}$ fueron causa y a la vez escenario de procesos de comunalización y (re)emergencia indígena que se tradujeron en movilizaciones por el reconocimiento jurídico de sus derechos. Entre ellos se destaca en primer lugar, la ley 23.302 "sobre política indígena y apoyo a las comunidades aborígenes" que impulsó la creación del Instituto Nacional de Asuntos Indígenas (INAI), normativa sancionada en 1985 a partir de una vieja demanda de organizaciones "setentistas" como la Asociación de Indígenas de la República Argentina (AIRA), el Centro Kolla y el Parlamento Nacional Indígena (Lenton, 2015). ${ }^{13}$ Posteriormente, ya en 1994, se producirá la incorporación del artículo 75 , inciso 17 , en la reforma de la Constitución Nacional, resultado de la persistente y hábil movilización de la militancia indígena de los 90 en Santa Fe. ${ }^{14}$ En ese contexto tuvieron lugar los festejos del V Centenario y sus contrafestejos. 
21 El gobierno del presidente Carlos Menem, en sintonía con su par español, concibió la conmemoración del inicio de la expansión europea en América como una vía para el posicionamiento simbólico de la Argentina en el conjunto de las naciones más desarrolladas. La Expo-América '92, ubicada en el nuevo Puerto Madero, expresión urbanista de la ideología neoliberal menemista en la Ciudad de Buenos Aires, aunó instalaciones monumentales conmemorativas de las carabelas y las ciudades españolas con algunas muestras sobre elementos de las sociedades precolombinas y stands de empresas amigas.

"Se recreó la costa europea con una carabela en tamaño original. El agua de los diques que divide en dos ese espacio simuló el Océano Atlántico. Del otro lado, se representó a América con una pirámide azteca. En la inauguración, la acción colombiana llegó a su paroxismo. El presidente de entonces, Carlos Menem, cruzó ese Océano en un barco y, como un moderno Colón, desembarcó frente a la pirámide (Masotta, 2013).

Además, en el que tal vez sea el gesto más elocuente del discurso oficial acerca del rol de la conquista española y su continuidad en la actualidad americana, se inauguró la base de datos virtual sobre la inmigración europea de fines del siglo XIX, frente a la cual los ciudadanos hacían largas colas para averiguar en qué barco o desde qué puerto partieron sus ancestros europeos.

lelamente, y con plena conciencia de la crítica que suscitaba el relato histórico de la conquista imperial, se rebautizó oficialmente a la fecha como "Encuentro de dos culturas". ${ }^{15}$ Tal como sucediera en la conmemoración del Centenario de la Conquista del Desierto impulsada por la dictadura en 1979 (Ottini, 2019), en 1992 gran parte del arco empresario y financiero se sumó jubilosamente, en la capital del país y en las provincias, a la exaltación triunfalista y obscena de la europeidad en América. ${ }^{16}$

Por su parte, los contrafestejos consistieron en su mayor parte en movilizaciones, marchas, recitales, foros, encuentros y jornadas académicas y de militantes, y publicaciones especiales. El debate estimulado por la conmemoración del V Centenario se combinó con la valoración de las posibilidades abiertas por la sanción de la ley 23302 y la demanda aún no cumplida de efectivización de la estructura legal del INAI, incluyendo la regulación de la participación indígena en la política indigenista, y continuó activo en jornadas en las que se dio lugar a la discusión de la inminente reforma constitucional.

Estas manifestaciones también fueron acompañadas por un amplio espectro social, que según algunos autores (i.e. Barragán y Mardones, 2015) aportó entre 9000 y 20.000 personas a las marchas de protesta. Más aún, la movilización contribuyó a la consolidación de ciertos colectivos, tales como los sikuris, que devinieron protagonistas de las manifestaciones indígenas en Buenos Aires de allí en adelante (Mardones, 2015).

\section{Asunto: $500^{\circ}$ Aniversario Descubrimiento de América}

A los fines de este artículo, seleccionamos tres legajos de la DIPPBA que se diferencian en características y extensión. ${ }^{17} \mathrm{El}$ primero y más breve, de apenas unas ocho páginas, procede de la Delegación Mercedes y data de junio de 1990. Se trata de un informe catalogado como Mesa "De", "Factor religioso", acerca de las "IV Jornadas sobre el V Centenario del descubrimiento y evangelización de América", organizadas en forma conjunta por la Universidad del Salvador, el Instituto del Profesorado de Mercedes y el 
Obispado de esa ciudad, y que poseen una perspectiva religiosa y favorable al descubrimiento.

El segundo legajo, "Asunto: $500^{\circ}$ Aniversario Descubrimiento de América", también catalogado en la Mesa "De", es el más extenso, con más de doscientas páginas, y reúne una gran variedad de informes, artículos y reportes de acciones varias de inteligencia ligadas a los festejos y contrafestejos. Abarca desde el 25 de octubre de 1991 hasta el 27 de octubre de 1992, es decir que refiere tanto a los sucesos previos como a los propios eventos ligados al aniversario.

El tercero es un informe producido por la "Delegación Tigre, Mesa antisubversiva Zona Norte”. Con casi 60 fojas, tiene en común con el informe anterior el seguimiento de actividades de contrafestejo, pero se destaca en particular por un extenso informe de casi cuarenta páginas de elaboración propia denominado "La Hispanidad", que intenta argumentar en favor del descubrimiento y en contra de las ideas antifestejos:

...Brevísima reseña de la labor evangelizadora de los Misioneros Hispanos -donde constan- aunque imperfectamente las formulaciones filosóficas y sustentos teóricos-históricos, válidos para rebatir los argumentos y las posturas anticatólicas, de la pseudo intelectualidad marxista que en estos días se encuentra activando intensamente en la faz de la cultura, cuestionando los festejos del $\mathrm{V}^{\circ}$ Centenario y preparando el terreno para eventuales acciones violentas y/o de hostigamiento, o movilizaciones que deriven en desmanes y /o desórdenes en la fecha de las celebraciones por intermedio del accionar operativo, de organizaciones pro-marxistas y de ultra izquierda. (DIPPBA, Mesa Ds "Varios", factor "policialideológico", Mesa antisubversiva Zona Norte, septiembre 1992).

Otra singularidad de este legajo es que forma parte de la Mesa "DS" dedicada a la delincuencia subversiva encuadrada en el factor "policial-ideológico". Coincidentemente, en sus apreciaciones traza un probable escenario de acciones terroristas en simultáneo en varios países como Argentina, Perú -a través de Sendero Luminoso- y España - vía la ETA (Euskadi Ta Askatasuna) - en el marco del 12 de octubre, y advierte acerca de posibles acciones conjuntas de la izquierda y diversas organizaciones para empañar y romper los festejos.

Esta catalogación podría relacionarse con el cambio de época tras la caída del Muro de Berlín y la desintegración de la Unión Soviética. Ese contexto pos guerra fría, según Muzzopappa (2000, p. 15), arroja un reajuste de los enemigos de la seguridad internacional, la cual, "al desaparecer del horizonte el claro objeto opositor" -el comunismo-, estaba en plena búsqueda ideológica de nuevos actores que desafiaran el sistema occidental representado en la democracia, la libertad y la economía de mercado. Así, las nuevas amenazas comenzarían a ser el fundamentalismo religioso (principalmente el islam), el terrorismo, el narcotráfico y los conflictos étnicos.

31 En tal sentido, "terrorismo" es un concepto a partir del cual se intenta definir y delimitar un cierto tipo de criminalidad. Presente en los debates de la comunidad internacional al menos desde fines del siglo XIX, ha resurgido una y otra vez a lo largo del tiempo y tomado renovados bríos tras el fin de la bipolaridad Este-Oeste y la consecuente reconfiguración hegemónica (Calveiro, 2012). El modelo que definió los términos de la conflagración mundial durante más de cincuenta años tenía dentro de su mapa conceptual una noción de terrorismo fuertemente ligada a las luchas entre bloques por el poder mundial (Ramos y Muzzopappa, 2017, p. 126).

En ese marco, y a la espera del choque de civilizaciones (Huntington, 1993), fenómenos como el levantamiento indígena en Chiapas serían observados como ejemplos de la 
nueva amenaza vinculada al terrorismo que influenciaría a las comunidades en Argentina. ${ }^{18}$ En esa línea de análisis, las Fuerzas Armadas harán confluir la necesidad de legitimar su rol tras su desprestigio posdictadura con la retórica en el ámbito internacional, asegurando que el comunismo y la subversión no se habrían extinguido, sino que habrían mutado (Muzzopappa, 2000, pp. 50, 95).

\section{A favor y en contra}

El informe de 1990 acerca de las "IV Jornadas sobre el V Centenario del descubrimiento y evangelización de América", realizadas en Mercedes, invita a pensar cuáles son los motivos que despiertan la atención de los servicios de inteligencia. No caben dudas de que el encuentro tuvo un propósito celebratorio; sin embargo la delegación local cubrió el evento, y en su apreciación se limitó a destacar a los organizadores y que se entregarían certificados, un análisis distinto al de otros acontecimientos en los cuales, con tono apocalíptico, se advierte sobre la gestación de conflictos o procesos revolucionarios o terroristas en ciernes. ${ }^{19}$

Si bien en los archivos predominan las acciones en torno a situaciones consideradas disruptivas o contestatarias, la cobertura de las Jornadas en Mercedes no es un caso excluyente. En abril de 1992 se elaboró un informe sobre la partida del velero "La Mimosa" desde Berisso, provincia de Buenos Aires, hacia España, desde donde volvería a zarpar para emular el viaje de Colón. El acto contó con la presencia de sesenta personas y autoridades locales,$^{20} \mathrm{y}$ aunque se trató de una iniciativa que intentaba homenajear el descubrimiento, también fue vigilada por la DIPPBA. ${ }^{21}$

Para mediados de 1992, meses antes del V Centenario, los informes de la DIPPBA ya daban cuenta de la organización de los contrafestejos y de los movimientos que participarían, muy particularmente los ligados a la izquierda, al peronismo y a organizaciones eclesiásticas vinculadas a la teología de la liberación, y de las personas participantes de cada una de ellas. Por el contrario, no se evidencia un acabado conocimiento de los referentes indígenas que, en ocasiones, y no con la misma asiduidad, aparecían en los informes.

Apenas aparece mencionada la comunidad de Los Toldos, provincia de Buenos Aires, que según el informe estaría infiltrada por el Partido Comunista y que haría que los mapuches (en general) fueran "propensos a reaccionar contra las celebraciones de los 500 años, agregándosele a esto que ya en el mes de abril el cacique [sic] Jorge Niancucheo [sic] se habría entrevistado con los Diputados nacionales Fernando De la Rúa (UCR) y Claudio Mendoza (PJ) en el Congreso nacional" (DIPPBA, Mesa "De", carpeta Varios, pp. 14 y 15. 1/7/1992).

La referencia a esta comunidad probablemente está sustentada en cierto conocimiento previo por parte de las agencias represivas. En principio, algunos miembros de la familia Cayuqueo -Magdalena, Marcelino y Félix, pertenecientes a dicha comunidadcuentan con legajos personales en la DIPPBA desde la década del 70, vinculados a posibles influencias del peronismo (Magdalena y Marcelino Cayuqueo) o por demandas teritoriales (Félix Cayuqueo). ${ }^{22}$

Por otro lado, es la única comunidad mencionada también en un informe de 1980, producto de un requerimiento de inteligencia a nivel nacional del mes de noviembre. La indagación solicitaba datos específicos acerca de cuatro colectivos: minorías 
extranjeras, migraciones internas, refugiados $\operatorname{asiáticos}^{23} \mathrm{y}$ poblaciones indígenas. Específicamente sobre población indígena, el requerimiento consulta sobre cuatro aspectos: asentamientos, características generales, localización geográfica y "sus principales problemas". La indagación posee un trillado sesgo metodológico e ideológico consistente en reconocer a los indígenas como tales solo en tanto vivan en comunidad, y en asumir como parte esencial de su existencia "sus problemas", sin que ello implique señalar responsabilidades. El resultado es previsible: "con respecto a esta población (indígena) existe únicamente en la localidad de General Viamonte (Los Toldos), estimándose que en su mayoría son descendientes de indígenas, calculándose en un 10\% del total de población de aquella ciudad" (DIPPBA, Mesa Referencia 17.901. Factor social. Requerimiento secreto. 10/11/1980, p. 19).

Así, este informe, mientras minimiza la presencia originaria en el resto de la provincia, resalta la excepcionalidad de la comunidad de Los Toldos. En breve, si hay indígenas, están allí.

No obstante, como adelantamos, la atención de la DIPPBA estaba focalizada en organizaciones y actividades de las que sospechan que tenían como objetivo final no tanto el V Centenario en sí, sino la utilización de dicha fecha como plataforma de lanzamiento de un frente opositor y revolucionario. Eso se esgrimía en un informe confidencial elaborado por la Delegación de Inteligencia de Lanús en julio de 1992:

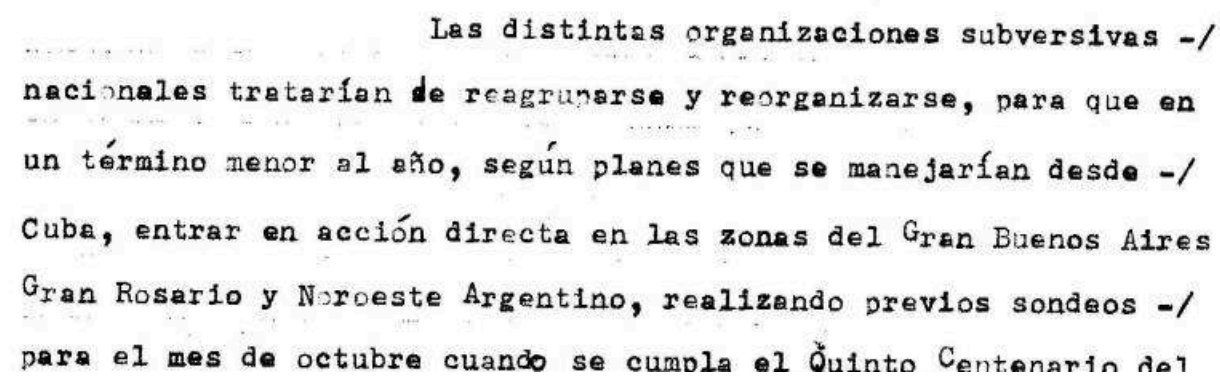

Imagen 1. DIPPBA. Captura del informe confidencial. Mesa "De", Varios: p. 130, 30/7/1992.

Buena parte de la atención de los servicios de inteligencia estaba puesta en el Movimiento Todos por la Patria (MTP) y su figura más reconocida, Enrique Gorriarán Merlo. El movimiento había tenido su pico de popularidad y trascendencia con el fallido ataque al cuartel militar de La Tablada en enero de 1989. La DIPPBA seguía también los pasos de Encuentro Cristiano, organización fundada en 1985, alineada con el Movimiento de Sacerdotes por el Tercer Mundo y la Teología de la Liberación, y vinculada al MTP hasta 1987 cuando ambas organizaciones se escindieron por diferencias en relación con las estrategias a seguir. Una de las figuras más emblemáticas de Encuentro Cristiano era el teólogo Rubén Dri, columnista de "Entre Todos", publicación del MTP que en aquel entonces otorgaba regularmente un espacio a temáticas vinculadas a los pueblos indígenas. ${ }^{24}$ 


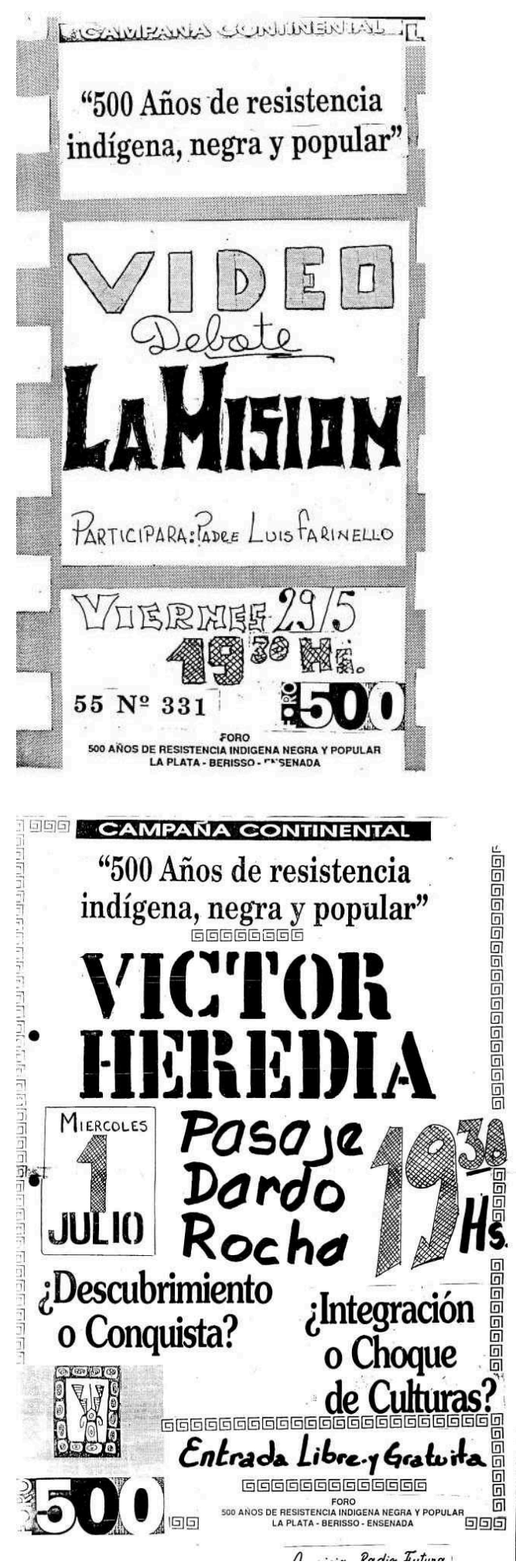

Imágenes 2 y 3. DIPPBA. Capturas de reproducción de Volantes del Foro 500. Mesa "De", Varios: pp. 49 y 50.

Mediante acciones sobre esas organizaciones, la Dirección de Inteligencia pudo reconstruir el derrotero del origen de los antifestejos a nivel internacional (1990 en Colombia y 1991 en Guatemala) desde donde se lanzó la "Campaña Continental 500 años de Resistencia Indígena y Popular" que confluiría en los contrafestejos en su tercera 
edición en Nicaragua. En Argentina tendría su correlato a través del Foro "500 Años de Resistencia Indígena Negra y Popular La Plata - Berisso - Ensenada" integrado también por el Peronismo de Base (PB) y otras organizaciones. Así, por un lado, la DIPPBA reunía y acopiaba frondosa información acerca de movimientos políticos y sociales tradicionales a los cuales señalaba como impulsores no solo de las contracelebraciones, sino también de poseer objetivos subversivos que se lanzarían después del 12 de octubre o que aprovecharían esa fecha para expresarse; mientras que por otro lado, ignoraba casi completamente el rol de los propios indígenas en los eventos del V Centenario en particular y en la vida política de la Argentina en general. Las escasas menciones de referentes indígenas en los informes tienen que ver con su vinculación con el peronismo:

[...] es de mencionar que en la ciudad de Moreno, más precisamente en la intersección de las calles Independencia y Belgrano, posee su sede el "MINJU" (Movimiento Indígena Justicialista), el cual se halla presidido por el Sr. ANGEL MONGELO, quien a su vez resulta ser miembro del FREJU local (Frente Justicialista) (DIPPBA. Informe sobre actividades en Morón y Moreno. 6/10/1992, pp. 140-144).

Lo preocupante del movimiento indígena para la agencia de inteligencia era que pudiera ser justicialista o que los indígenas pudieran ser captados por el peronismo. En cambio, se mostraba indiferente a la precisión en los datos referidos a los propios indígenas. Así se manifestó el 8 de octubre de 1992 cuando tuvo lugar un acto solidario con el pueblo Mapuche en el que intervinieron "el presidente de los mapuches TAIN KINEGETUAN" (sic) y Hector Paine como principal orador, y que contó con la adhesión de Víctor Heredia y las actuaciones de artistas populares como Teresa Parodi, "Marta Pierén" (sic) y “Jorge Mazziali” (sic) entre otros. ${ }^{25}$

\section{Un nobel para Rigoberta}

Si hay una situación que a la DIPPBA le permitió aunar su desconocimiento sobre el mundo indígena con los temores y presagios acerca de una inminente revolución local con nexos internacionales, esa fue la campaña por el Nobel de la Paz a Rigoberta Menchú Tum.

Uno de sus puntos más altos fue el recital del 9 de julio de 1992, organizado en el microestadio de Ferro por el "Foro 500" frente a dos mil espectadores, y que contó con una decena de bandas musicales. Se destacó la presencia de León Gieco quién presentó Cinco siglos igual. ${ }^{26}$ 


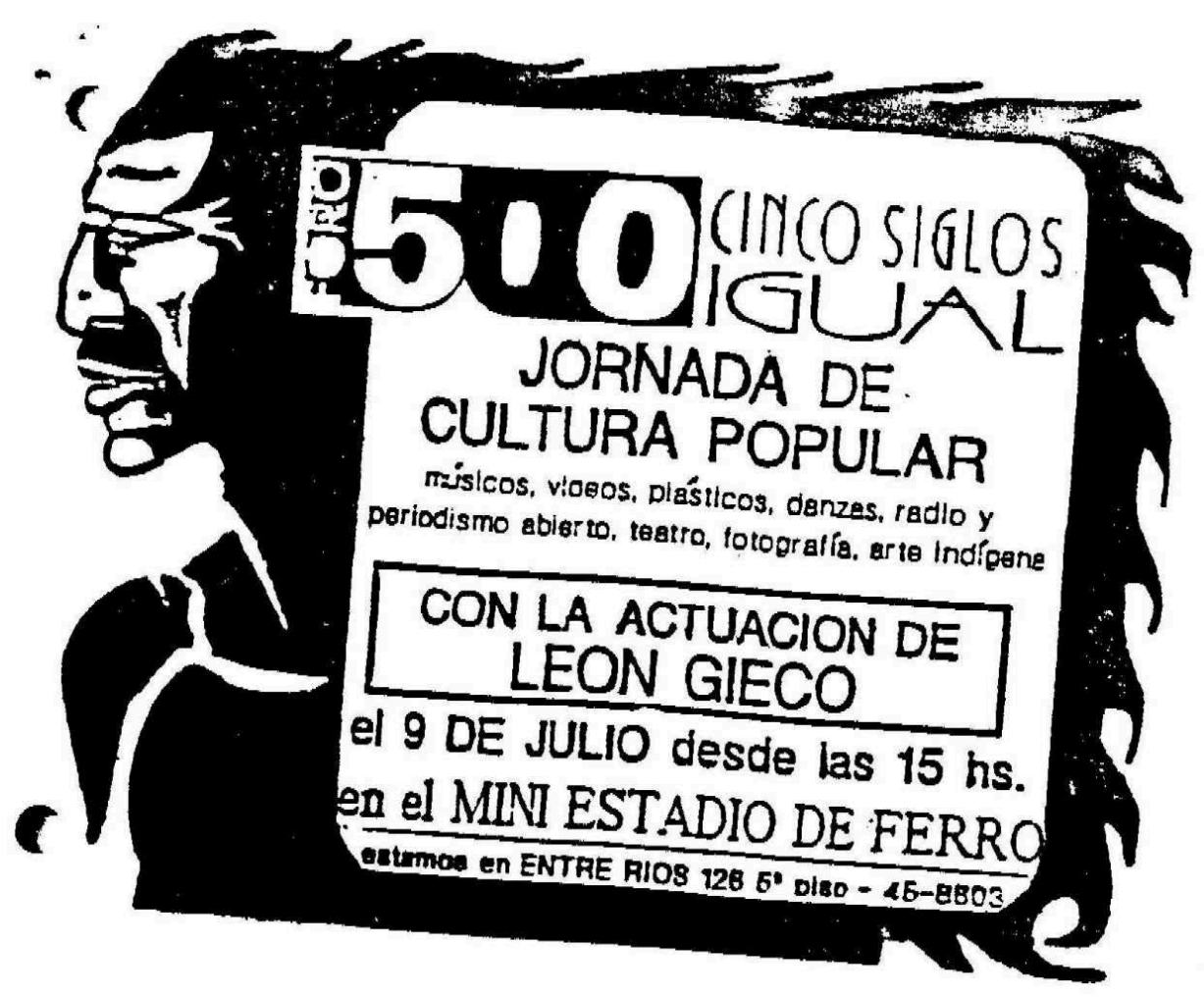

Imagen 4. DIPPBA. Captura de reproducción de Volante del Foro 500. Mesa "De", Varios: p. 53

"Foro 500" era la denominación sintética de "Foro 500 años de resistencia indígena negra y popular La Plata - Berisso - Ensenada", lanzado en marzo de 1992, que estaba formado según la DIPPBA por elementos del peronismo de base, sectores de izquierda y Encuentro Cristiano. En el evento del 9 de julio de 1992 se recolectaron firmas para la campaña por el otorgamiento del Premio Nobel de la Paz a la líder guatemalteca, gestión que luego se replicó en diversos espacios y formatos (volanteadas, charlas, jornadas, etc.) y que llamó la atención de la DIPPBA.

En los informes se señala la participación de las Madres de Plaza de Mayo, del Frente de Agrupaciones Indias y de la Unión de Mujeres de la Argentina (UMA). En el primer caso, para la policía la ligazón entre las Madres y la subversión es inescindible; en el segundo, nuevamente, se señala la participación indígena bajo una denominación de frente, pero sin mayor conocimiento de los "activistas" originarios más que su aglomeración en el colectivo "indios". En el último caso, se trataba de una organización interna del Partido Comunista Argentino que también estuvo bajo la vigilancia de la DIPPBA. Rotulada como "colateral" del partido, pese a expresar demandas transversales vinculadas al género, ${ }^{27}$ la inteligencia policial entendía dichas consignas como una "finalidad aparente" que ocultaba los verdaderos objetivos ligados al comunismo disolvente, dado que "su "finalidad real" era "fomentar la disconformidad y resistencia al gobierno por parte de las obreras, criticando las medidas económicas y gremiales (Marengo, 2015, p. 121). ${ }^{28}$

Entendemos que son notorias las dificultades de la DIPPBA para discernir matices, modalidades y reconocer referentes de los movimientos indígenas, aún más en el contexto de un imaginario colectivo que los daba por extintos o descendientes lejanos de una identidad en disolución. 
Estas perspectivas no menguaron la preocupación de los servicios de inteligencia respecto a lo que se gestaba en torno al V Centenario, y se acentuó aún más cuando la líder guatemalteca visitó la Argentina en agosto de 1992. El evento principal se desarrolló el 28 de ese mes en la Catedral de Quilmes, cuando, a media mañana, Rigoberta Menchú Tum fue recibida por el obispo Jorge Novak y Adolfo Pérez Esquivel y una delegación de distintos organismos de derechos humanos, como Madres de Plaza de Mayo, Asamblea Permanente por los Derechos Humanos (APDH) y Amnesty Internacional, entre otros. La convocatoria, según la propia DIPPBA, fue de alrededor de 500 personas incluyendo a delegaciones de escuelas de la zona.

51 El informe sobre "el acto religioso 212/1" es detallado y da cuenta de la presencia de agentes de inteligencia en la Catedral. Además de la nómina de los presentes, ${ }^{29}$ detalla los principales argumentos de los discursos, entre los que se destacan la denuncia de los 46.000 desaparecidos en Guatemala y el cuestionamiento al "V Centenario del descubrimiento de América, trazando una construcción elíptica en cuanto a que más que descubrimiento se trata de un encubrimiento, por el genocidio de culturas autóctonas" (sic) (DIPPBA. Información relacionada con la presencia de Rigoberta Menchu Tum, en Quilmes. Mesa “De" Factor Social, 27-08-1992).

\section{Los contrafestejos del V Centenario}

52 La documentación de la DIPPBA de octubre de 1992, como es lógico, es más profusa. El corpus ofrece: a) coberturas periodísticas acerca de los actos en Argentina y otras partes del mundo; b) informes sobre actos en La Plata y Capital Federal; c) memorandos acerca de las actividades previas de difusión y organización de distintos organismos en toda la provincia de Buenos Aires; d) folletos, gacetillas y afiches de la convocatoria; y e) detalladas descripciones por agentes infiltrados en las marchas, actos y conferencias. Solo en octubre de 1992 el legajo "Asunto 500 Aniversario Descubrimiento de América. Actos" reunió unas 90 fojas sobre el tema, casi todas concentradas entre el 6 y el 13 de ese mes.

Veamos el informe acerca del acto central en la Capital Federal. El mismo es antecedido por la recopilación de acciones en otras localidades bonaerenses (Mar del Plata, Chascomús y La Matanza) y se complementa con diversos artículos periodísticos sobre el evento. 


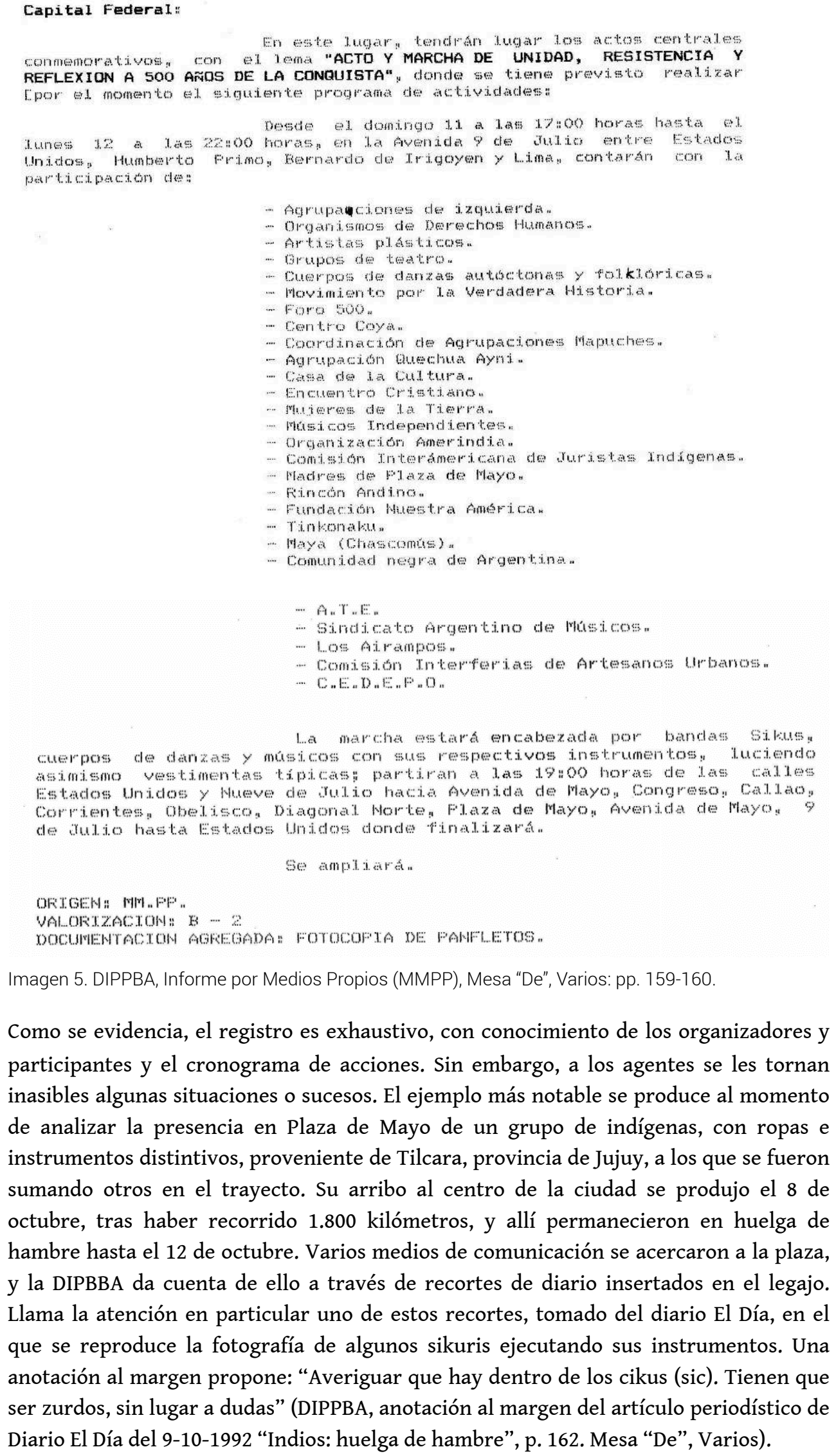

Imagen 5. DIPPBA, Informe por Medios Propios (MMPP), Mesa "De", Varios: pp. 159-160.

Como se evidencia, el registro es exhaustivo, con conocimiento de los organizadores y participantes y el cronograma de acciones. Sin embargo, a los agentes se les tornan inasibles algunas situaciones o sucesos. El ejemplo más notable se produce al momento de analizar la presencia en Plaza de Mayo de un grupo de indígenas, con ropas e instrumentos distintivos, proveniente de Tilcara, provincia de Jujuy, a los que se fueron sumando otros en el trayecto. Su arribo al centro de la ciudad se produjo el 8 de octubre, tras haber recorrido 1.800 kilómetros, y allí permanecieron en huelga de hambre hasta el 12 de octubre. Varios medios de comunicación se acercaron a la plaza, y la DIPBBA da cuenta de ello a través de recortes de diario insertados en el legajo. Llama la atención en particular uno de estos recortes, tomado del diario El Día, en el que se reproduce la fotografía de algunos sikuris ejecutando sus instrumentos. Una anotación al margen propone: "Averiguar que hay dentro de los cikus (sic). Tienen que ser zurdos, sin lugar a dudas" (DIPPBA, anotación al margen del artículo periodístico de Diario El Día del 9-10-1992 “Indios: huelga de hambre”, p. 162. Mesa “De”, Varios). 

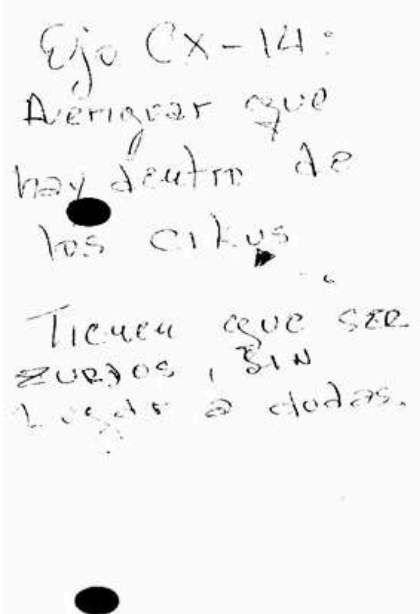

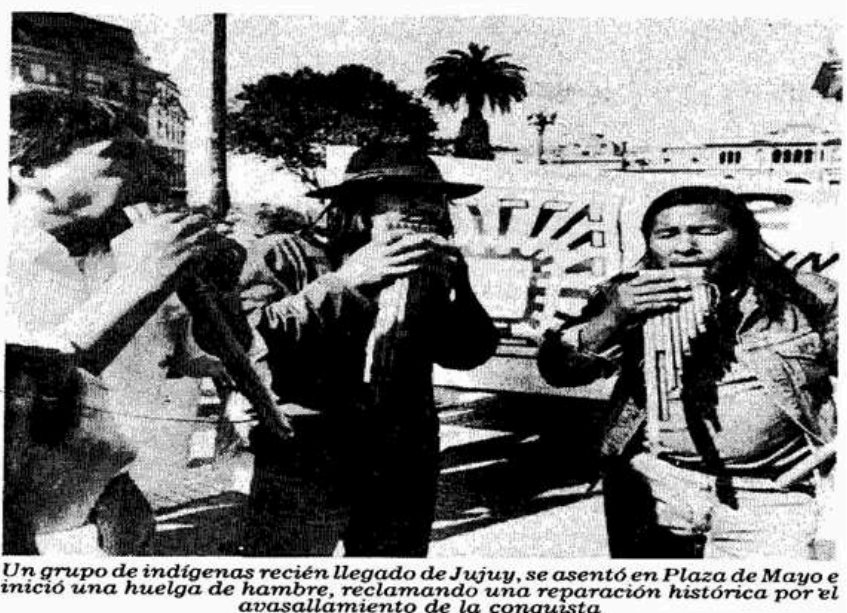

Indios: huelga de hambre Representantes de comunidades indigenas llegaron ayer a Plaza de
Mayo, tras recorrer 1.800 kilómetros desde el Norte, e iniciaron en ese
paseo historico una huelga de hambre que se prolongará hasta el lunes, 12 pesectubre.
Ese dia, aniversario del Descubrimiento de América, concluirá aquí la Ese dia, aniversario del Descubrimiento de América, concluira aquí la
movilizacion de los pueblos indios que reclaman una reparacion historica
por el avasallamiento que sufrieron con la conquista.

Imagen 6. DIPPBA, anotación al margen del artículo periodístico de Diario El Día del 9-10-1992 "Indios: huelga de hambre". Mesa "De", Varios: p. 162.

Evidentemente, la aparición de los pueblos indígenas en la arena pública incomoda y se vuelve escurridiza de catalogar. Se sospecha mucho y se ignora casi todo, desde la posibilidad de que los indígenas se organicen y posean demandas políticas específicas (de ahí el "tienen que ser zurdos") hasta los materiales de los instrumentos y la consecuente fantasía de "sikus rellenos", posible arma revolucionaria.

Este desconcierto no era excluyente de la DIPPBA. En sus archivos se guarda un artículo publicado a fines de octubre de 1992 por el conocido periodista y exespía Carlos Manuel Acuña en el diario La Prensa con un título terminante y elocuente: "Indigenismo, terrorismo y narcotráfico son lo mismo" (DIPPBA, Mesa "De", carpeta varios, pp. 216. 27/10/1992). La relación establecida entre pueblos indígenas y terrorismo podría resultar cómica si no fuera un tópico al que la prensa y los servicios de inteligencia suelen acudir, aun hoy, para justificar represiones frente a las demandas de los pueblos originarios. ${ }^{30}$

\section{Conclusiones}

El análisis de este corpus documental nos permite reconstruir la concepción de los servicios de inteligencia postdictadura acerca de los indígenas, sus formas de existencia, su potencial de movilización política y eventualmente su "peligrosidad". Como expresamos más arriba, el reconocimiento de los individuos y grupos indígenas es en realidad muy escaso en relación con la reiterativa elucubración de sus motivaciones. Las posibilidades de conocimiento profundo del movimiento indígena parecen ser esquivas frente al deseo de control por parte de la agencia estatal; aun cuando no parece ser difícil - hasta hoy- compensar este vacío con proyecciones acerca de la intencionalidad disruptiva y la vocación terrorista de toda acción política indígena (Muzzopappa y Ramos, 2017). 

analizado por Mariana Tello Weiss (2019), que describe con densidad etnográfica las acciones y agentes de Montoneros en Córdoba, las producciones de la DIPPBA no muestran capacidad de indagación demasiado profundas. Ambas agencias coinciden, en cambio, en la "larga duración" de sus actividades, que se extienden más allá de los límites temporales de la dictadura. Por ende, es necesario un enfoque integral que permita explicar la criminalización de la movilización política indígena en el marco de una modalidad represiva estatal que no se agota en los gobiernos de facto. su catalogación como "nuevas amenazas" a la seguridad internacional en una etapa pos guerra fría. Desde esa óptica, cuando los indígenas se organizan y reclaman y no responden a los estereotipos a los que se los reduce, como la pobreza vivida con resignación, propia del denominado "indio permitido" (Hale, 2004; Rivera Cusicanqui, 2016), se concluye que son ingenuos, confundidos o manipulados por otros que les proveen "letra" y recursos (Muzzopappa, 2000; Lazzari y Lenton, 2019).

En definitiva, como vimos, el temor de la DIPPBA tenía más relación con la conformación de un frente opositor, subversivo, de perfil peronista o de izquierda que capitalizara las demandas indígenas, que con las propias organizaciones y sus reclamos en el marco del V Centenario. Esta inclinación es subsidiaria de una larga deuda, entre muchas otras, de la ciudadanía y las instituciones respecto de los pueblos originarios: la del reconocimiento de su agencia política en relación con una historia común.

\section{BIBLIOGRAPHY}

Barragán, F. y Mardones, P. (2015). Che Sikuri. La expresión del siku en el contexto porteño. Su rol en las dinámicas de reproducción aymara - quechuas y su constitución como parte de la identidad cultural de la Ciudad de Buenos Aires. III Congreso Latinoamericano de Antropología (ALA).

Santiago, Chile.

Borja, J. y Mascareñas, T. (1992). El V Centenario y la imagen de España en el mundo. Anuario Internacional CIDOB 1992. Dossier Relaciones exteriores de España, 89-96.

Briones, C. (1999). Weaving "the Mapuche People": The Cultural Politics of Organizations with Indigenous Philosophy and Leadership [PhD Dissertation]. Graduate School of The University of Texas at Austin.

Briones, C. (2005). Cartografías Argentinas. Políticas indigenistas y formaciones provinciales de alteridad. Buenos Aires: Antropofagia.

Calveiro, P. (2012). Violencias de Estado. La guerra antiterrorista y la guerra contra el crimen como medios de control global. Buenos Aires: Siglo Veintiuno Editores.

Catela, L. da Silva y E. Jelin (2002). Los archivos de la represión: documentos, memoria y verdad. Madrid: Siglo Veintiuno de España editores.

Corpus, Vol. 11, № 1 | 2021 
CPM - Comisión Provincial por la Memoria (s.f.). Historia institucional de la DIPPBA. [On line] Disponible: www.comisionporlamemoria.org

Escolar, D. (2005). El “estado de malestar”. Movimientos indígenas y procesos de desincorporación en la Argentina: el caso Huarpe. En C. Briones. (Ed.), Cartografías Argentinas. Políticas indigenistas y formaciones provinciales de alteridad, (pp. 45-79). Buenos Aires: Antropofagia.

Espósito, G. y Catela, L. da Silva (2013). “Indios”, “comunistas” y “guerrilleros”: miedos y memorias de la lucha por tierras en las tierras altas de Jujuy, Argentina. Corpus. Archivos virtuales de la alteridad americana, III(1), 1er. semestre 2013 [On line] Disponible en: http:// ppct.caicyt.gov.ar/index.php/corpus

Funes, P. (2006). Secretos, confidenciales y reservados. Los registros de las dictaduras en Argentina. El Archivo de la Dirección de Inteligencia de la policía de la Provincia de Buenos Aires [DIPBA]. En H. Quiroga y C. Tcach (Comps.), Argentina 1976-2006. Entre la sombra de la dictadura y el futuro de la democracia, (pp.199-232). Santa Fe.

Hale, C. (2004). Rethinking Indigenous Politics in the Era of the 'Indio Permitido'. NACLA Report on the Americas, $\mathrm{n}^{\circ} 38,2004 / 2,16-21$.

Jaschek, I. K., Lanteri, M., Sahade, J.y Soler, E. (2018). La Comisión Provincial de la Memoria y el fondo documental de la Dirección de Inteligencia de la Policía de la Provincia de Buenos Aires (DIPPBA). Tres estrategias posibles para pensar las políticas de acceso. Hilos Documentales, 1(1). Archivo Histórico de la Universidad Nacional de La Plata.

Kahan, E. (2007). ¿Qué represión, qué memoria? El “archivo de la represión” de la DIPBA: problemas y perspectivas. Revista Question (16). Facultad de Periodismo y Ciencias de la Comunicación de la Universidad Nacional de La Plata.

Lanteri, M.; Kahan, E.N.; Sahade, J.; Iuliano, R.M.; Bogliano, V.; Balbuena, Y.; Mannarino, J.; González Canosa, M.; Balut, P.; Bugnone, A. (2005). La mirada de la DIPBA (Dirección de Inteligencia de la Policía de la Provincia de Buenos Aires) sobre el movimiento estudiantil platense [en línea]. IV Jornadas de Sociología de la UNLP, 23 al 25 de noviembre de 2005, La Plata, Argentina. En Memoria Académica.

Lazzari, A. y Lenton, D. (2019). The Indians and Politics. Transgressive Indigeneities in Political Activism before and after State terrorism in Argentina. Journal of Intercultural Studies, Taylor \& Francis Online. XLI, 2019, London and Canberra. [On line] Disponible en: https:// www.tandfonline.com/doi/abs/10.1080/07256868.2019.1675617

Lenton, D. (28-31 de octubre de 2009). Memorias de la represión de la militancia originaria en Argentina durante la última dictadura militar (1976-1983). En P. Funes y P. Flier (Coords.), Formas de reconstrucción del pasado reciente: Historia y Memoria de las dictaduras en Argentina y el Cono Sur. XII Jornadas Interescuelas, Departamentos de Historia, Mesa 10.2, Bariloche.

Lenton, D. (2015). Notas para una recuperación de la memoria de las organizaciones de militancia indígena. Identidades, 5(8), 117-154.

Lenton, D. (2018). De genocidio en genocidio. Archivos de la represión a la militancia social indígena. Revista de Estudios sobre Genocidio, XIII. CEG-UNTREF, Buenos Aires. [On line] Disponible en: http://www.revistasuntref.com.ar/index.php/reg/issue/view/21

Lenton, D., Rodríguez, M., Szulc, A., Matarrese, M., Trentini, F., Tolosa. S., Aguzin, C, Elichiry. V., y Goñi, J. (2018). Apuntes antropológicos sobre pueblos indígenas y violencias en la Argentina 
contemporánea. Revista QueHaceres, 4, Departamento de Ciencias Antropológicas, Facultad de Filosofía y Letras, UBA.

Mardones, P. (2015). Buenos Aires Jacha Marka. Migrantes aymaras y quechuas en Buenos Aires en los umbrales de un nuevo pachakutik [Tesis Doctoral en Ciencias Antropológicas]. Facultad de Filosofía y Letras, Universidad de Buenos Aires.

Marengo, M. E. y Castronuovo, S. (2015). El archivo policial como espacio de memoria: un sondeo por el ex archivo de la DIPPBA. Revista Electrónica de Fuentes y Archivos, VI(6), 106-125.

Masotta, C. (1992). Descubrir América. Video, 20 min.

Masotta. C. (miércoles 24 de julio de 2013). El pedestal de Colón. Página 12. [On line] Disponible: https://www.pagina12.com.ar/diario/sociedad/3-225158-2013-07-24.html

Muzzopappa, E. (2000). Metáforas estratégicas. El concepto de cultura en y sobre el ámbito de la seguridad [Tesis de Licenciatura en Ciencias Antropológicas]. Facultad de Filosofía y Letras, Universidad de Buenos Aires.

Muzzopappa, E. y Ramos, A. (2017). Una etnografía itinerante sobre el terrorismo en Argentina: paradas, trayectorias y disputas. Antípoda. Revista de Antropología y Arqueología (29), 123-142.

Nagy, M. (2012). Tradiciones situadas, usos del pasado y devenir indígena: la "Conquista del Desierto" y la construcción de hegemonía en la provincia de Buenos Aires [Tesis Doctoral]. Facultad de Filosofía y Letras, Universidad de Buenos Aires.

Nagy, M. (2013). Una educación para el desierto argentino. Los pueblos indígenas en los planes de estudio y en los textos escolares actuales. Espacios en Blanco, 23, 187-223.

Nagy, M. (septiembre de 2017). Partidos, sindicatos, movimientos y comunidades: Una mirada a las trayectorias militantes indígenas en la provincia de Buenos Aires. X Seminario Internacional de Políticas de la Memoria, Centro Cultural Haroldo Conti, Buenos Aires, .

Nagy, M. (2018a). Experiencias generacionales militantes de la población originaria en Buenos Aires. Prácticas de oficio, II(22), 112-124.

Nagy, M. (2018b). Un relato perdurable: La realización simbólica en el genocidio de los pueblos originarios en Argentina. Revista de Estudios sobre Genocidio (UNTREF), IX (13), 63-79.

Nagy, M. (2021). La Semana Nacional de la Conquista del Desierto de Trenque Lauquen y la Dirección de Inteligencia de la Policía de la Provincia de Buenos Aires: evocación militarista, evento vigilado. Revista de Estudios Marítimos y Sociales (REMS), Mar del Plata (UNMDP).

Ottini, S. (2019). Espejos Genocidas: el homenaje al centenario de la Conquista del Desierto durante la última dictadura cívico militar en Argentina [Tesis de Licenciatura]. Facultad de Filosofía y Letras, Universidad de Buenos Aires.

Papazian, A. (2013). El Territorio también se mueve. Relaciones sociales, historias y memorias en Pulmarí (1880-2006) [Tesis doctoral]. Facultad de Filosofía y Letras, Universidad de Buenos Aires.

Pérez, P. (2015). Futuros y fuentes: las listas de indígenas presos en el campo de concentración de Valcheta, Río Negro (1887). Nuevo Mundo Mundos Nuevos (en línea).

Rivera Cusicanqui S. (2016). Etnicidad Estratégica, Nación y (Neo) colonialismo en América Latina. Revista Alternativa $\mathrm{N}^{\circ}$ 5. Universidad Nacional de Córdoba, Primer semestre de 2016.

Rodríguez, S. (2011). Conmemoraciones del cuarto y quinto centenario del 12 de octubre de 1492. Revista de Estudios Sociales, 38, 64-75. 
Tello Weiss, M. (2019). El represor como antropólogo: apuntes para la lectura etnográfica de un manuscrito contrainsurgente. Corpus. Archivos Virtuales de la Alteridad Americana, IX(2) [On line] Disponible en: https://journals.openedition.org/corpusarchivos/3092

Trouillot, M. R. (1995). Silenciando el pasado. El poder y la producción de la Historia. Granada: Comares.

\section{NOTES}

1. La investigación que sustenta este artículo fue realizada gracias al aporte del proyecto UBACYT (Secretaría de Ciencia y Técnica de la Universidad de Buenos Aires) 20020150100041BA y del PICT (Fondo para la Innovación Científica y Tecnológica, Ministerio de Ciencia y Técnica de la Nación) 2016-2124. Versiones preliminares del trabajo fueron expuestas en las IV Jornadas de la Red de Estudios sobre Represión y Violencia Política (Rosario, 2019) y en las I Jornadas de Historia Reciente de la Pcia. de Buenos Aires (UNGS, 2019). Además, una versión abreviada y traducida fue publicada en la revista Urban Anthropology, vol. 48, N 3-4 (New York, 2020). Este trabajo es continuidad de las investigaciones de sus autores en CONICET. Agradecemos al Dr. Santiago Garaño sus comentarios y sugerencias, y a la Dra. Mariana Katz por sus orientaciones para el acceso a los archivos. También agradecemos al Prof. Jorge Cayuqueo su valiosa colaboración en la búsqueda de documentación.

2. Hasta ese entonces recibió diversas modificaciones al calor de reformas policiales, constitucionales o cambios de gobierno. Ver http://www.comisionporlamemoria.org/archivo/ladippba/. Durante el período que trata este artículo, la jefatura de la Policía bonaerense fue ejercida por Pedro Klodczyk.

3. Ley 12.642/01, artículo 2, incisos A y B.

4. En este punto es oportuno remarcar que, dado el proceso de invisibilización de la población indígena en nuestro país, no contamos con archivos específicamente indígenas o relativos a procesos o políticas de represión sobre los mismos. En tal sentido, la documentación suele obtenerse de archivos diversos que alojan información sobre otros tópicos, tarea que, como señala Pilar Pérez, pretende "la reconstrucción de los fragmentos de un 'archivo estallado"'. Es decir, la búsqueda y reunión de la documentación oficial -en triangulación con fuentes no oficiales- que se encuentra alojada en diferentes dependencias, principalmente estatales, conservada bajo una aparente no-lógica (o una lógica en algún punto desconfigurada) en diferentes archivos provinciales, nacionales y locales. Informes, documentos, partes, memorias, "papeles sueltos" que, a pesar de su desvinculación con cualquier tipo de serie persiguen un ordenamiento burocrático propio de los estados modernos. Estos documentos existen y se encuentran albergados, aunque prácticamente invisibilizados, en diferentes reservorios (2015, p. 10).

5. Ver Lenton (2015), Nagy (2017).

6. Entendemos que ambos no son términos excluyentes. Cabe destacar que la singularidad de dichos acervos tiene que ver con que no fueron pensados para su consulta, sino como dispositivos de control o represión de la sociedad civil y en tanto hoy se pueda acceder a ellos, se convierten -en términos de da Silva Catela- en "territorios conquistados". Ver Catela y Jelin (2002) y Kahan (2007).

7. Para la clasificación completa y su análisis puede verse Marengo y Castronuovo (2015).

8. La elección de la sede tuvo lugar en 1986 y se impuso en gran medida gracias a los votos de los países latinoamericanos.

9. Diario El Día, 22-4-1992, en DIPPBA, Mesa "De", Carpeta Varios, p. 6.

10. Diario El Día, 22-4-1992, en DIPPBA, Mesa "De", Carpeta Varios, pp. 8-9. 
11. Ver, por ejemplo, "Contrafestejos en el 12 de octubre". Diario El Tiempo, 13/10/1992. https:// www.eltiempo.com/archivo/documento/MAM-221957

12. Diego Escolar (2005) propone la noción de "estado de malestar" para definir la crisis del estado de bienestar y las reformas del Estado impuestas en el marco de la hegemonía neoliberal, y cómo éstas han alterado drásticamente los movimientos, prácticas y subjetividades políticas e impactado sobre las representaciones colectivas de identidad.

13. La ley 23.302 "sobre política indígena y apoyo a las comunidades aborígenes" sancionada en 1985 declaró de "interés nacional la atención y apoyo a los aborígenes y a las comunidades indígenas existentes en el país, y su defensa y desarrollo para su plena participación en el proceso socioeconómico y cultural de la Nación, respetando sus propios valores y modalidades" (art. 1). Para tales objetivos se planteó la creación del Instituto Nacional de Asuntos Indígenas (INAI) (Art. 5) y diversos planes y modalidades de reconocimiento y participación indígena.

Ver http://servicios.infoleg.gob.ar/infolegInternet/anexos/20000-24999/23790/texact.htm

14. El artículo 75 inciso 17 de la Constitución Nacional de 1994 establece que "corresponde al Congreso: Reconocer la preexistencia étnica y cultural de los pueblos indígenas argentinos; Garantizar el respeto a su identidad y el derecho a una educación bilingüe e intercultural; Reconocer la personería jurídica de sus comunidades y la posesión y propiedad comunitarias de las tierras que tradicionalmente ocupan y Regular la entrega de otras aptas y suficientes para el desarrollo humano. Ninguna de ellas será enajenable, transmisible ni susceptible de gravámenes o embargos".

15. Desde un principio, las organizaciones de activismo indígena repudiaron el eufemismo con tanta contundencia como habían criticado con anterioridad la celebración de la Raza Hispana. Un tiempo antes, el referente del Centro Kolla, Asunción Ontiveros Yulquila, escandalizó a su auditorio definiendo el "encuentro de culturas" como una violación, reclamando que se identificara a la mal llamada "Madre Patria" como al "padre violador" de la madre americana (Lenton, notas de campo, 1990).

16. El corto documental Descubrir América realizado por Carlos E. Masotta registra y expone el proceso de construcción e inauguración de la Expo-América 92, en el contexto de la transformación urbana del momento (Masotta, 1992).

17. Algunos de los documentos que se describen en las secciones siguientes han sido reproducidos por la CPM en su página oficial www.comisionporlamemoria.org

18. Esta línea argumental se aplicó especialmente para interpretar el conflicto en Pulmarí, Neuquén, a fines de la década de 1990 (Briones, 1999; Muzzopappa, 2000; Papazian, 2013).

19. DIPPBA, Mesa "De", Entidades Religiosas - leg. 2878.

20. DIPPBA, Mesa "De", carpeta Varios, pp. 7, 10 y 11. 26/4/1992.

21. En probable que las operaciones de inteligencia sobre eventos -a priori- no disruptivos o celebratorios de alguna efeméride oficial puedan resultar llamativas; no obstante, la propia DIPPBA cuenta con antecedentes al respecto. Por ejemplo, entre 1966 y 1973 realizó tareas de espionaje en Trenque Lauquen, provincia de Buenos Aires, durante la Semana Nacional de las Campañas al Desierto, un evento que celebraba la fundación de la ciudad y el conjunto de hechos y procesos denominados como Conquista del Desierto. Ver Nagy (2021)

22. Ver Nagy (2017, 2018a); Lenton (2015).

23. La categoría refugiados asiáticos aparece diferenciada de la de minorías extranjeras debido a que en 1979 el gobierno de la dictadura se había ofrecido a refugiar mil familias laosianas que escapaban de las secuelas de la Guerra de Vietnam. La Junta Militar se ofreció a recibir 1000 familias, aunque solo 293 arribaron al país. La mayor parte provenía de Laos (266 familias) y el resto de Camboya (21) y Vietnam (6). Ver: http://www.mininterior.gov.ar/poblacion/pdf/ Documento07). Según algunos testimonios, esta propuesta no se habría originado por una cuestión humanitaria sino para evitar la designación de un relator especial para el caso argentino debido a las denuncias que recibía el gobierno por desapariciones forzadas, y que en 1979 
desembocarían en la visita de la Comisión Interamericana de Derechos Humanos (CIDH). Ver https://gatopardo.com/reportajes/exodo-de-laos-argentina/

24. Por ejemplo, en distintas ediciones la revista Entre Todos publicó una crónica acerca del Tantanakuy, fiesta popular celebrada en Jujuy; una entrevista al sacerdote Rubén Capitanio, quien denunciaba la grave situación y la explotación de la población mapuche en los parajes aledaños a Piedra del Águila, provincia de Neuquén; una nota sobre la organización y demandas de una comunidad wichí de 200 familias en Embarcación, Salta y los pormenores de la sanción de la Ley Indígena en Río Negro y las exigencias de las comunidades mapuche por participar de su elaboración. (Ver "Crónica del Tantanakuy", Entre Todos, Año 2, n 15, p. 39, marzo 1986; "Junto al Limay, pobres en una provincia rica", Entre Todos, año 2, n 17, p. 10, mayo 1986; "Wichis de Salta. La semilla, la escuela, el respeto", Entre Todos, año 2, n 18,14 junio 1986; "Los paisanos exigen su participación", Entre Todos, año 3, n²9, p. 12, junio 1987).

25. DIPPBA. Informe sobre acto solidario con el pueblo mapuche, 8/10/1992, p. 166. El informante (el Sargento Ramírez, de la Sección Capital) no solo desconocía la organización política mapuche al inventarle un presidente, confundiendo el nombre de la organización urbana Taiñ KiñeGetuam, surgida pocos años antes, con un nombre personal, sino también de algunos artistas no indígenas, cuyos nombres fueron consignados con errores (Mazziali por Marziali y Pieren por Pirén).

26. Cinco Siglos Igual es un tema musical de León Gieco, artista popular vinculado y comprometido con las organizaciones de derechos humanos, que denuncia la tragedia de la Conquista de América y en ese momento era material inédito de lo que sería su próximo disco (Mensajes del Alma, 1992).

27. Entre ellas, "la lucha por la defensa de la mujer, el hogar y el niño, salarios igualitarios por el mismo trabajo; la libertad por los presos políticos y gremiales y la defensa por la paz" (Marengo, 2015, p.121).

28. Otro aspecto importante en relación con el movimiento indígena es la dificultad de los agentes de la DIPPBA para realizar seguimientos exhaustivos o directamente infiltrarse, condicionante similar al que Marengo remarca para la Unión de Mujeres Argentinas (UMA), en tanto el personal de inteligencia se nutría exclusivamente de varones y por tanto los informes abundaban en datos sobre el afuera, esto es los maridos, acompañantes, las patentes de los autos, duración de la reunión, etc. pero no en lo que se hablaba o decidía (Marengo, 2015, p.121). Algo similar a lo que Emanuel Kahan señaló de los seguimientos a las organizaciones judías, muchas de ellas exclusivas para miembros de la comunidad: “...el 3 de agosto de 1962, el Club Max Nordau auspició una exposición de libros en iddish (sic) y castellano y se encomendó al oficial de la DIPPBA verificar que no se encuentre en infracción el Art. $2^{\circ}$ del Decreto № 4965/59 del P.E. Nacional (Prohibía las actividades del Partido Comunista y sus entidades afines). Sin embargo, el agente B-6 ve frustrada su tarea, como deja ver en su informe del 20 de agosto del mismo año: -no se ha podido concurrir en razón de la concurrencia exclusiva de elementos pertenecientes a la colectividad"; o, la fórmula menos sutil: "estos tres actos [unas conferencias dictadas durante la exposición] no han podido ser controlados en razón de que la concurrencia en forma exclusiva pertenece a la colectividad israelita, no pudiendose (sic) infiltrar sin pasar desapercibido" (Kahan, 2009, pp. 71-72).

29. Sobre Madres de Plaza de Mayo se asegura que asistieron seis de ellas pero "ninguna de relevancia" (sic). Además se reporta la presencia del Centro de Estudios Legales y Sociales (CELS), una delegación de Comunidades Eclesiales de Base encabezada por el padre Luis Farinello, la Directora General de Escuelas Graciela Giannetassio y múltiples políticos como el intendente de Quilmes Aníbal Fernández (Partido Justicialista), los diputados Rita Basualdo por la Unión Cívica Radical (UCR) y Jorge Drkos del Partido Intransigente. 


\section{ABSTRACTS}

The Intelligence Boureau of the Police of the Buenos Aires Province (DIPPBA) was created in 1956 and dissolved in 1998. The DIPPBA guided its actions through the articulation of a logic of national order, aimed at sustaining the proscription of Peronism, and another of international order, in relation to the National Security Doctrine and the creation of an internal enemy in the framework of the Cold War.

In this article we analyze the documentary collection of the DIPPBA to point out this source's wealth for understanding the policies of repression of the indigenous movement in the second half of the 20th century. In particular, we focus on the records produced by the monitoring and intelligence actions regarding the celebrations and counter-celebrations motivated by the $\mathrm{V}$ Centennial of the Conquest of America, in 1992. These are files that gather information about different intelligence actions deployed in the province of Buenos Aires to spy, especially, those who showed a critical position in relation to the arrival of Columbus in America, but also, surprisingly or not, those who reproduced the celebratory tone of the anniversary. Indeed, the DIPPBA attributed to the activities and groups that were observed the gestation of opposite or revolutionary fronts with international support and linked to terrorism. We also observe the discomfort generated by indigenous organizations and claims insofar as they do not respond to the collective stereotypes to which they are usually reduced.

La Dirección de Inteligencia de la Policía de la Provincia de Buenos Aires (DIPPBA) fue creada en 1956 y disuelta en 1998. La DIPPBA orientó sus acciones a través de la articulación de una lógica de orden nacional, destinada a sostener la proscripción del peronismo, y otra de orden internacional, en relación con la Doctrina de la Seguridad Nacional y la creación del enemigo interno en el marco de la Guerra Fría.

En este artículo analizamos el fondo documental de la DIPPBA para señalar la riqueza de esta fuente para la comprensión de las políticas de represión del movimiento indígena en la segunda mitad del siglo XX. En particular, enfocamos los registros producidos por las acciones de seguimiento e inteligencia respecto a los festejos y contrafestejos motivados por el $\mathrm{V}$ Centenario de la Conquista de América, en 1992. Se trata de legajos que reúnen información acerca de distintas acciones de inteligencia desplegadas en la provincia de Buenos Aires para espiar, especialmente, a quienes mostraban una postura crítica en relación con la llegada de Colón a América, pero también, sorprendentemente o no, a aquellos que reproducían el tono celebratorio de la efeméride. En efecto, la DIPPBA atribuía a las actividades y grupos observados la gestación de frentes opositores o revolucionarios con apoyo internacional vinculados al terrorismo. Observamos también la incomodidad que generan las organizaciones y los reclamos indígenas en tanto no responden al imaginario colectivo al que se los suele reducir.

\section{INDEX}

Palabras claves: Indígenas, movimiento, organizaciones, represión, inteligencia

Keywords: Indigenous, movement, organizations, repression, intelligence 


\section{AUTHORS}

\section{DIANA LENTON}

Instituto de Ciencias Antropológicas, Universidad de Buenos Aires

y Consejo Nacional de Investigaciones Científicas y Técnicas, Argentina.

Correo electrónico: dianalenton@gmail.com

\section{MARIANO NAGY}

Instituto de Ciencias Antropológicas, Universidad de Buenos Aires y Consejo Nacional de Investigaciones Científicas y Técnicas, Argentina.

Correo electrónico: nagy.mariano@gmail.com 